Journal of the

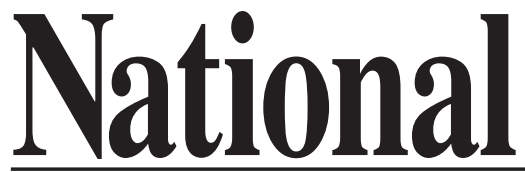

Academy or

Forensic
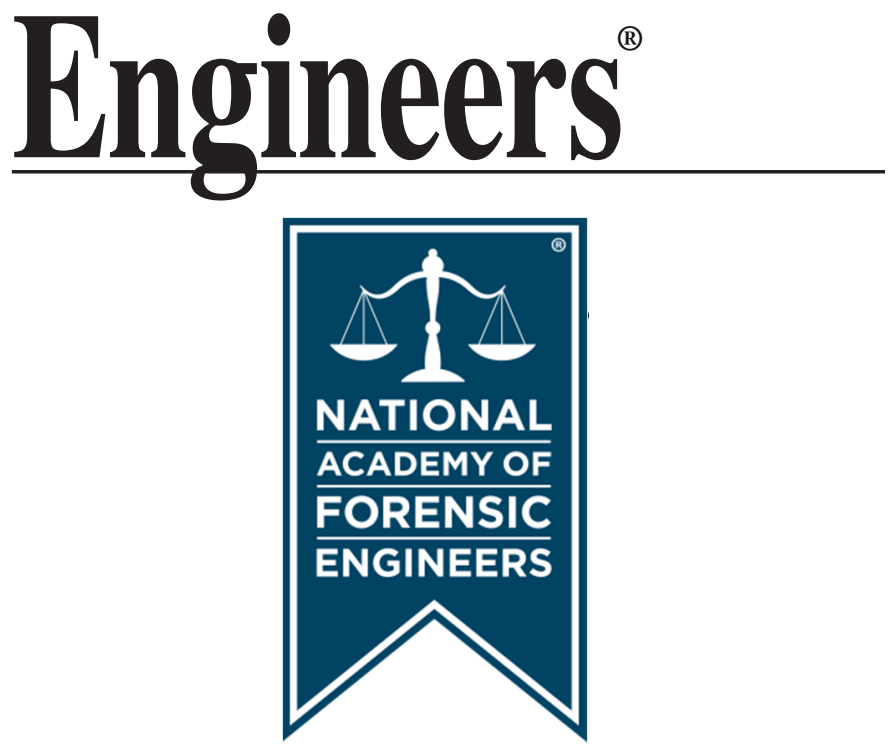

http://www.nafe.org ISSN: 2379-3252 


\section{Multi Party Joint Forensic Engineering Investigations in Litigation and Mediation/Arbitration "The Joint Field Survey Process"}

by Rik F. van Hemmen, P.E., (NAFE 431S)

\section{Introduction}

In order to reduce the amount of disagreements at the resolution stage of the damage to an absolute minimum, the marine industry, over a period of many years has established a procedure that addresses the investigation into cause, and efforts at repairing damage, while also streamlining the eventual question as to who is ultimately going to pay for the damages.

This procedure is called the joint field survey.

The intent of the joint field survey is to produce a written field survey report.

In the marine industry, properly performed field surveys and properly prepared field survey reports have greatly reduced the extent of later dispute resolution, and have greatly reduced the costs to the responsible party.

This paper will discuss the joint field survey process and will make suggestions as to how it can be applied in the non-marine field.

\section{A Marine Incident}

Typical marine incidents involve groundings, sinkings, collisions, damage due to heavy weather, fires, explosions, machinery failures, or acts of negligence.

Immediately after the incident the vessel's master will take any actions that he feels are necessary to stabilize the situation.

As soon as the situation is stable he will notify the vessel's Owner and advise him where he intends to take the vessel to evaluate the damage, or make repairs. 
The master might elect to take the vessel to its intended destination, or a port of refuge, or if the incident is serious, the vessel might be placed under tow and under the care of salvors.

The master will be making entries in the vessel's logbook with regard to the incident and he might be preparing a separate statement of facts.

\section{Calling The Field Survey}

Once the vessel is in a suitable location the Owner wants to make plans to return the vessel to service as soon as possible, this is accomplished through the field survey process.

In the marine industry the term "field survey" signifies an on-site inspection.

It is important to note that the Owner is always in charge of the field survey process.

The term "Owner" can be cloudy in the shipping industry, since the Owner of a vessel could be a person, or a financial institution that is not at all involved in the operation of the vessel itself.

In shipping, the term "demise owner" is sometimes used, this term is reserved for the party that behaves as if he were the Owner, such as a bareboat charterer (someone who long term leases a vessel).

The bareboat charterer in turn may engage a vessel managing company that operates the vessel, or for a particular incident may engage a consultant. Any of those parties can function as Owner by consent during the field survey.

When the vessel becomes available for survey at a port, repair facility or other convenient location, the Owner will notify all parties involved in the particular voyage the vessel is engaged in, provide them with the date for joint survey, and will cordially invite them to attend.

It is in the Owner's interest to set the survey date as soon as possible since a speedy agreement on how to proceed after the incident will reduce the costs of delay to a minimum.

Furthermore, the passage of time could result in additional damages, or could result in alteration or spoilage of evidence that could be instrumental in determining the cause of the damage. 
At the same time, the Owner should not arrange for a field survey so quickly that it is impossible for everybody to attend.

In practice it should be possible for any party or a designated representative to make it to the field survey location within 24 hours of being notified.

Figure 1 provides a list of parties that often are found to attend a field survey.

Not all parties listed will be required to attend on all types of field surveys.

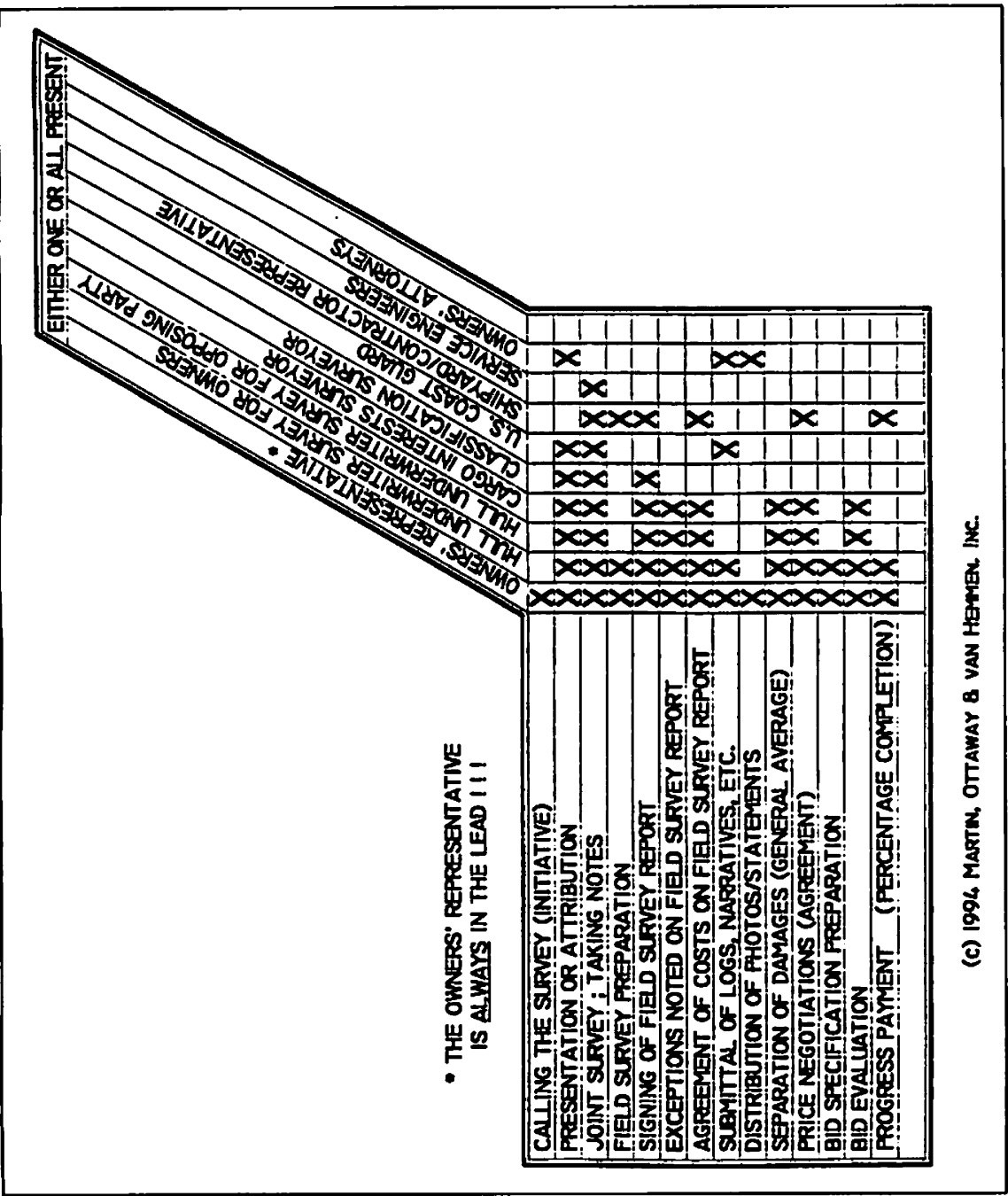

Figure 1 
It is important to note that there are three types of attendees. One group of attendees consists of parties financially involved in the venture, another group consists of people that regulate the actions taken by the parties involved in the venture, and the last group attends in a support function.

The parties that are financially involved could be underwriters of the various types, ship owners, and/or cargo owners.

Depending on the type of damage, they could also require the attendance of other parties (third parties) that might be related to the cause of the damage, such as a shipyard that had recently performed work on the vessel and that would now appears to have failed, or in the case of a collision, parties representing the other vessel.

The regulatory agency representatives ensure that the actions agreed on are legal and can be safely executed.

The support group could be structural specialists, rigging specialists, repair contractors or equipment specialists that function in an advisory fashion to ensure that the proposed repair procedures are the safest and most economical.

Any party can choose not to attend, but generally does so at its own risk. Once repairs are made, evidence will have been lost, and it will be difficult for a party that has chosen not to attend to effectively defend itself against a claim, or to criticize the actions taken upon completion of the field survey.

With regard to all parties attending, it should be realized that there is an absolute requirement for total technical competence in the subject matter.

Important decisions are made during field surveys, and an attendee who is not familiar with the technical details of the matter at hand, will inevitably disrupt the process.

While attorneys are noted in figure 1, they do not, and should not contribute anything to the field survey process since the field survey is entirely technical and requires no legal input.

To have no input in a process that can have legal implications is extremely unnerving for attorneys, and will be further discussed under the "Involvement by The Legal Profession" section below.

\section{The Field Survey}

The most important function of the field survey is to establish as much agree- 
ment as possible about the cause, nature, extent, and the recommended repair of the damage.

At the beginning of the field survey the Owner provides a basic background description of the incident to all attending parties.

This description can be in written form, and is then called the "Narrative" and in that case will be prefaced with the following sentence:

"The following was reported and understood:"

The description should not be detailed; it should merely describe time. place, and date issues relevant to the subject incident.

If the vessel was involved in a collision, the narrative should describe the vessel's time and place of departure, the type and amount of cargo the vessel is carrying if there are cargo issues involved, the vessel's departure draft, the intended destination of the vessel and estimated time of arrival and approximate time and place of the incident.

The details provided should make it possible for the attendees to be able to make informed decisions with regard to the type of repairs that would be most economical.

For example, if nothing is known about the cargo and its destination, it would be difficult to decide if the most economical method of repair would include transshipment of the cargo or not.

The narrative should not provide details that attempt to explain the root cause of the damage, or that place blame.

The Owner writes the narrative, but it is not part of the signed field survey report, and is not signed by the other parties since it is not related to actual observations or technical decisions made.

Nevertheless, the Owner has a serious burden to provide accurate information since decisions made during the field survey could be based on information provided by the Owner, and any misleading information in the narrative would negatively reflect on the Owner's reputation.

The next step in the field survey is the actual damage inspection.

The damage inspection can take many forms. In case of a steel damage 
caused by heavy weather it might involve a quick inspection, while a collision damage inspection might take a full day involving photos, video tapes and careful measurements.

Some inspections could take weeks and attendees might vary from day to day depending as to whether the activities of that day are relevant to their particular interest or not.

The intent of the inspection is to develop a picture of the damage that is complete and unambiguous. In this regard any attendee can point out features of the damage or the surrounding area that he believes to be relevant, or make comments that could further clarify the situation.

Therefore, if a piece of equipment is found to be damaged, but also severely deteriorated or appeared to have been already non-functional prior to the incident, such a condition should be pointed out by an attendee at the time of the survey.

Once the extent of the damage has been determined, preliminary repair options will be discussed.

For steel repairs, discussions will take place about the amount of steel to be replaced, and where to make the cuts for renewal. For equipment repairs, discussions might take place to decide as to whether the piece of equipment should be repaired or renewed, or if the piece of equipment should be repaired in place or removed to a repair facility.

At any time during the inspection it is expected that nobody withhold his particular comments or suggestions.

The Owner's representative will make consistent efforts to ensure that everybody gets a chance to speak and to voice their concerns.

While in recent years there has been a tendency for every attendee to take their own photographs and even videos, it is much preferable if only one individual takes photographs, as directed by any of the attendees.

Taking one set of photographs avoids confusion at a later stage, avoids endless exchange of many duplicative sets of photographs at a later stage, and removes questions of authenticity of photographs.

At times professional photographers are engaged by mutual agreement to take care of the photography. 
Often it is necessary to open a component to make repairs. However, opening a component can disturb important evidence needed for the determination of the cause of damage.

This results in a dilemma that needs to be resolved before repairs can be made.

There is no standard approach for resolving this dilemma. However, the joint aspect of the field survey provides a forum for developing an approach that balances both technical needs to find a cause and technical needs for making repairs.

In complex investigations an Owner will often produce a preliminary disassembly protocol. This protocol gets finalized at the field survey so the unit can be opened according to the protocol at the field survey.

During a field survey it is also possible to agree to perform further detailed examinations of a particular component.

The component can be removed and taken to a laboratory for further examination under controlled conditions.

Since there has been no change in ownership of the component simply by removing it from the vessel, in general the component will stay in the custody of the Owner. However he may elect to assign custody to a different party.

Lube oil and fuel oil samples generally can be easily split and therefore multiple samples are often taken and distributed to interested parties, although it is questionable if there is a benefit in performing independent analyses.

Metallurgical examinations are a typical example of the type of specialist examinations that could be beyond the immediate expertise of the attending parties. If metallurgical examination appears to be an issue in determination of cause, interested parties often have a metallurgist present at the field survey.

It is then customary that the metallurgists present agree on removal of samples and the type of tests and examinations that would be appropriate.

Again it is customary that the Owner makes the final decision as to where the samples will be taken for further examination.

Ideally all metallurgists will then perform a joint examination of the samples at the Owner's designated facility, and issue a joint fact report, containing 
results of chemical analyses, strength tests, microscopic examinations, and observations made.

The metallurgical report should provide metallurgical discussion of findings, such as "the failure surfaces observed are typical of low cycle fatigue that started at the keyway", but should not provide opinions as to the cause of the low cycle fatigue.

It would be inappropriate for a specialist report to voice an opinion into cause, especially since the overall investigation by the main survey party may not have been completed yet.

The main survey party should issue the joint opinion with regard to cause, obviously with the benefit of the expertise of the various metallurgists.

Every member of a field survey party should get an opportunity to personally inspect a damage. Sometimes this can be a tedious process if a particular damage is in an inaccessible location and can only be seen by one person at a time.

In case of a diver's survey it is impossible to personally inspect a damage and the surveying party will have to rely on a diver's report or the diver's video.

Nevertheless even with a diver's survey the general jointness approach applies, and all parties should be able to provided reasonable directions to the diver prior to the survey and to be able to ask questions to the diver after his survey.

\section{The Field Survey Report}

Upon completion of the inspection a field survey report is prepared.

This written report summarizes the findings and serves as an agreement between all parties at interest that the recommended repairs noted in the report are the most reasonable and economical at that stage of the incident.

A Field Survey report has no letterhead. A field survey report is a joint document and as such it is inappropriate to make it appear that one party was the originator.

The report has a preamble that identifies the vessel, the date, the place of the survey, the type of damage and the time and place when the damage occurred, or was first discovered.

Next, it describes the damages and recommended repairs in the "Found and 
Recommended" section. In most reports the damages will be outlined in great detail in column format with detailed recommended repairs written across from each damage item.

Each damage item is numbered sequentially.

After the damage listing there is a "Notes" section that outlines agreement of additional activities and expenses that will be involved in returning the ressel to service.

The "Found and Recommended" damage descriptions are always specific to the incident.

However, under the "Notes" section of the report some of the associated costs might not be related to this damage incident alone.

For example, a note: "Necessary safe repair berth to be provided" might also be related to other repairs the Owner might be performing concurrently.

Therefore agreement on a safe repair berth to be provided does not necessarily mean that all costs associated with the repair berth are immediately related to this damage in full.

The portion of the repair berth costs that will be assigned to this damage is an adjustment or a legal question and is generally not determined by the technical parties attending the survey.

Following the "Notes", are the "Surveyor's Notes".

The Surveyors' notes generally deal with procedure. They outline further actions that have or will be taken as agreed at the field survey.

If the field survey process has not been completed it is important to note in the field survey report how the process will continue.

It often happens that a field survey report gets generated on a partial survey, but that the field survey report fails to clearly establish as to how the survey will be completed.

This is counterproductive to the process and should be avoided.

In certain cases it will be possible to agree on a cost to repair the damage, and that also can be included in the field survey report. 
In marine surveying the operative term with opinions on cost is "fair and reasonable", which means that the costs are not necessarily the lowest, but rather the best that can be achieved under the circumstances.

The survey is ended with the sentence: "Survey made without prejudice"

This is an abbreviation of a longer sentence that could vary depending on who attends the survey. From an underwriter's point of view it could say: "Survey made without prejudice and subject to underwriter's liabilities and/or policy terms and conditions."

Depending on who attends, their "without prejudice" version would vary, and consequently it is generally written in this abbreviated version.

What "survey made without prejudice" really means is that all participants agree that the agreement made is the most reasonable and economical regardless of whom ultimately will be responsible for payment.

The signatures of the attending parties follow "Survey made without prejudice".

This is the moment when the matter comes to its technical conclusion, and when the experienced and knowledgeable professionals are separated from the amateurs.

A professional will know, based on his training and experience, that the agreement reached in the field survey report will be the best possible remedy to avoid future problems. He will not hesitate to sign a field survey that has been agreed upon between professionals and in which he has been able to participate to the full extent.

However, a person with insufficient experience and training will not have the confidence to sign a field survey report for the simple reason that he is not entirely sure that it fairly represents the best possible technical remedy.

Despite the best intentions of all parties, there will be situations where no agreement can be reached on a specific item.

As noted before, at all times the Owner keeps control of the field survey report, and he can decide what it states. 
Nevertheless, it is also in the Owner's best interest to reach full agreement and sometimes a minor compromise at the survey report writing stage will resolve larger issues and vastly improve the chances of a speedy resolution of an incident.

If full agreement cannot be reached, the field survey report will contain the Owner's view of the damage situation and other attendees can sign the field survey report with exception taken to specific items.

In that case next to a person's signature, for example, a note as follows can be added: "with exception taken to the extent of damage under item $\mathrm{X}$ where this surveyor is of the opinion that the damage only extends to frame Y." or, "with exception taken to item X, which in this person's opinion was caused by wear and tear rather than heavy weather."

In recent times it has become less common to include agreement on cause in the signed section. This will be discussed further under "The Cause of Damage" below.

Sometimes measurement sheets or sketches are included with the field survey report.

Traditionally photographs were not made part of the field survey report. This was probably related to the fact that transmitting photographs was difficult in the days of telex.

There is no reason why photographs cannot be included in a field survey report, but inclusion of too much extraneous detail can make the generation of the field survey report unwieldy and time consuming, and therefore can make it difficult to get all the parties to sign the report prior to their departing from the scene.

A surveyors' note stating that copies of all photographs will be provided to all attendees in the next few weeks can be included in the field survey report.

Another surveyors' note would identify attachments to the field survey report.

It is entirely appropriate to prepare a handwritten field survey report. A handwritten field survey report is generally prepared more quickly, and therefore does not delay the signing by all the parties who each might be on tight travel schedules. 
written in pencil using carbon paper to produce copies.

Fortunately today it is easier to make photocopies of the handwritten original.

Strike outs and erasures are no problem, as long as the copies and the original are showing the same.

Often only the original is signed and all parties are provided with photocopies of the signed original, sometimes copies are made of the unsigned original and the original and copies are individually signed. This appears to be a matter of personal preference and appears to have no bearing on the authenticity of the document.

The moment the field survey report is signed it can be considered to be binding on a technical level between all invited parties. The document shows technical agreement on technical matters. However, this does not mean that the nature, cause, and extent of damage and recommended repairs are carved in stone.

Once the recommended repairs outlined in the field survey report are started it is entirely possible that new damage is discovered, or it is discovered that the recommended repair procedure cannot be effectively performed.

At that time, the Owner will call for further survey and will again invite all interested parties to further inspect damage.

The report that results from such supplementary survey is called a supplementary survey report, and only describes conditions that have changed, or describes additional damage items.

Additional damage items are numbered sequentially starting one higher from the last item in the last report, or if they modify items in an earlier report, refer to the particular item number in that report.

Supplementary field survey reports are identified as "first supplementary field survey report", "second supplementary field survey report", "third supplementary field survey report", etc.

From a logistics point of view is advantageous to keep the number of supplementary field survey reports to a minimum.

In this regard every effort should be made to make each field survey report as complete as possible. 
Sentences such as "repairs to be made as appropriate" or, "as found necessary", or, "extent to be further investigated on a later date" are generally counterproductive.

Figure 2 shows a field survey report that dates back a few years. While not identical in format to today's version of a proper field survey report, it contains many of the elements discussed above.

This report was written on September 18,1934 following the fire and stranding of the SS "MORRO CASTLE".

This incident still is embroiled in controversy as far as the actual initiation of the fire is concerned.

Regardless of what initiated the incident, the Owners and underwriters of the vessel were faced with a vessel that was on the beach a few feet away from the boardwalk in Asbury Park, NJ, and that needed to be removed, repaired or scrapped.

While the costs associated with this incident at $\$ 4,000,000$ were substantial, especially in pre-war dollars, the actual report is quite short and simple.

It is an agreement between the parties that were involved in resolving the consequences of the fire, that the damages resultant from the fire exceeded the vessel's insured value and that it would be most economical to scrap the vessel.

The report does not have a detailed damage description, and does not list recommended repairs.

However, in this case it must have become evident to all parties that the cost to repair the damage easily exceeded the insured value of the vessel, and therefore only a general description of the damages was necessary.

The report does not have the standard "Without Prejudice" line, but the US Government representative added his own without prejudice statement.

Three of the four signers to the document hold special relevance in the history of field survey development.

Mr. Compton signed for the London Salvage Association, who probably represented London Underwriters (Lloyds) as technical advisors, Mr. Bull signed for the US Salvage Association, representing US underwriters, and $\mathrm{Mr}$. Martin signed for the Owners of the vessel. 
Mr. Martin, at that time, was the Owner of the firm this author is presently associated with, and performed a function in 1934 that this firm still performs on a regular basis today.

The (London) Salvage Association was, and is, the foremost worldwide marine underwriters' surveying firm, and the US Salvage Association was a US start-up version of the The Salvage Association predominantly serving the US marine insurance market.

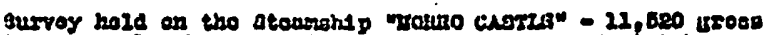
tong - whls aho tro $2 y$ lng burnod and etronded at dabuzy Park, How Jorvej, as Japtemor 10, 1034.

tho sollowing centlaman woro preaonts

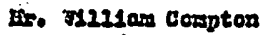

roprogontsag Londen anvuge nogoosatsar.

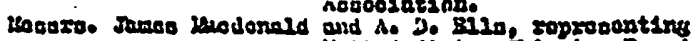

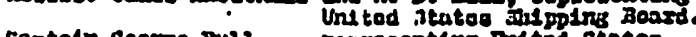

captaln coosse Bull sopresontsns untted otated

2tre. D. A. Darten

salvego dosoolatson. roprosonting Orners of the otwasintp Hozro Cantio".

Tho reasel rao sound 2y1rus broadaldo to the beach, bor polnting noxth, about 200 orf conrontion gell stos and wh th about a 200 21at to otarboarde.

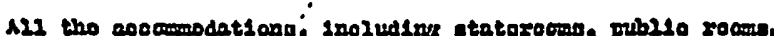

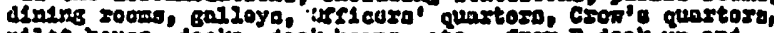
p120t houso, dooke. deok benma, ote. Jxea $D$ deok up and from itam to atorn wore omplotoly dantsoyod oy ftre. ..

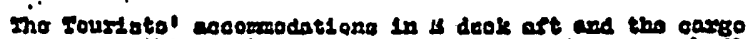
pacas on this deok, Iroluding rokstarextad apacos, badiy darnged by 8150 and patur, 1roludins dook pletes, boam, ato.

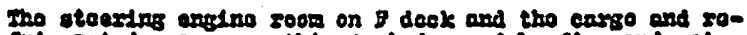

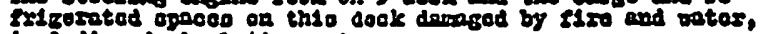
inciuder aces plating, ote.

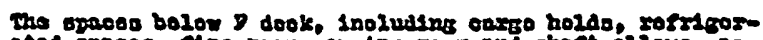

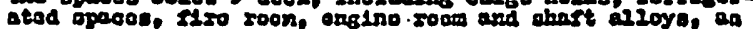
fas. as oould bo nocortalned, woro past dasioged by stro, and thooe ontiso opecos Eloodod.

$\therefore$

it the timo of the axamination, wtos we found throughout tho yogool in all oargo holdo and machinory opaces up to

About tho lovel or the in dook, of I deak.

Bpidanco. of 2120 tra sound in tho areino soom and tho lovol. of the vator in this opeco was up to about tho oontos. or the mals tustriog.

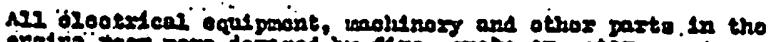

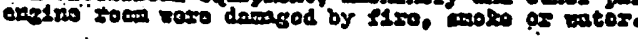

Tho sirezoen was sound in a almilar condltson.

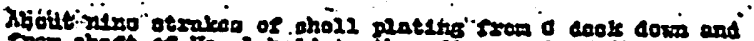
on tho port and 1700 i hold to tho artax part of the poesol,

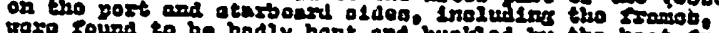
tho sound to bo badiy bant and buoked of. tho boat frow 


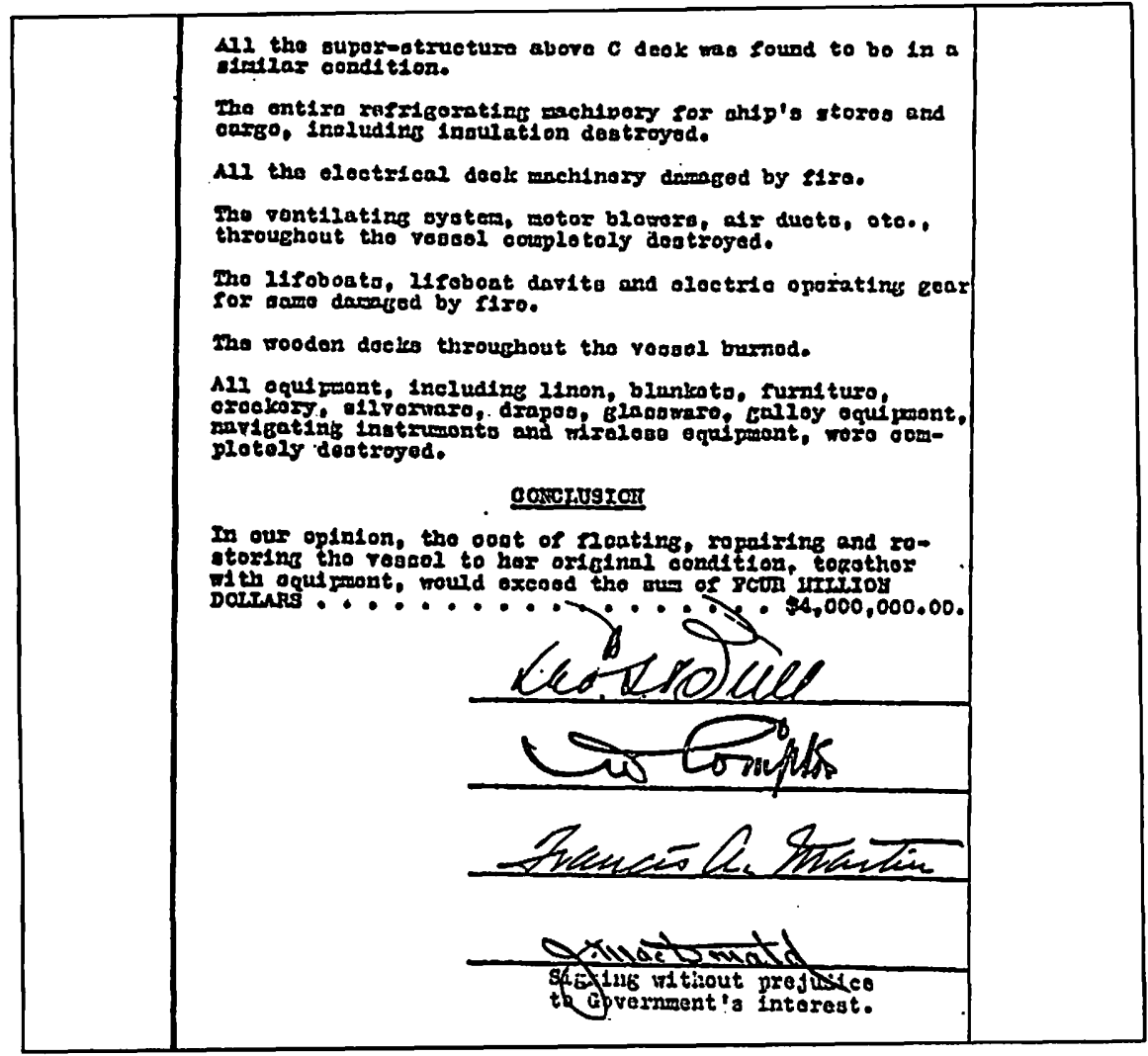

Figure 2 continued

While the Salvage Association was no stranger to the Field Survey concept. it was Captain Bull of the US Salvage Association who started the formalization of the Field Survey report process, in an effort to provide better service to shipowners.

The US Salvage Association came to realize that it would better serve hoth Owners and Underwriters if the cause, technical and cost portion of a claim could be resolved in the field, and therefore specifically directed its surveyors to participate to the fullest extent possible in the Field Survey process.

The US Salvage Association even went further by directing their surveyors to write the field survey for the Owner if the Owner did not prepare it himself.

The underwriters in general terms encouraged this process because once the technical issues and the repair costs were agreed upon, it was only the question of liability that remained to be resolved. 
The US Salvage Association issued formal procedures to its surveyors for the writing of field surveys, and informally their procedures are still followed today, although the US Salvage Association is no longer in existence.

The Field Survey process is still used by The Salvage Association, especially in the United States, and Martin, Ottaway, van Hemmen \& Dolan, Inc. is one of the major proponents of this process.

\section{The Cause of Damage}

The "cause" portion of the field survey report can provide some pause for thought even for the most experienced field surveyor.

It would be nice from an Owner's point of view to state a preamble as follows:

We, the undersigned, have this date held survey on the M/V "NEVER WRONG" in order to ascertain and agree upon, or as noted otherwise, the cause, nature, extent and recommended repairs of collision damage resulting from the negligence of the M/V "ALWAYS RIGHT" on January 1, 2000.

To any attending surveyor this would be totally unacceptable, since he would have no clue if the ALWAYS RIGHT was negligent or not.

The preamble could be changed to:

We, the undersigned have this date held survey on the M/V "NEVER WRONG" in order to ascertain and agree upon, or as noted otherwise, the cause, nature, extent and recommended repairs of damage sustained as a consequence of contact with the M/V "ALWAYS RIGHT" on January 1, 2000.

This preamble could be acceptable, if the vessel is new and generally clean, if it has been established with unambiguous reports that there was a collision between the two vessels and if there were a clear damage pattern from just one colliding vessel.

If it turns out that there were multiple impact points that might have resulted from a number of different collisions, a surveyor might sign with exception taken to the cause and extent of the damages noted, or might insist on a preamble as follows:

We, the undersigned, have this date held survey on the M/V "NEVER WRONG" in order to ascertain and agree upon, or as noted otherwise the cause, nature, extent and recommended repairs of damage sustained as a consequence of impact with unknown object(s) on or about January 1, 2000. 
Some surveying organizations have directed their surveyors to avoid any discussion of the cause of a damage in the field survey report, and allow the Owners to add their allegation of the cause of damages only after the signatures.

While this avoids an often difficult subject, it reduces the effectiveness of the field survey report, insofar that the reasonable common ground never gets established as far as the cause is concerned.

As this example shows, everything is open for discussion and negotiation during the production of a joint field survey report.

This does not suggest that the production of a field survey report requires an endless amount of haggling and negotiating. Between experienced surveyors the process is fast and effective.

In the end the process is simple, the field survey report only contains information that has been actually observed or verified and makes recommendations that are mutually considered to be reasonable from a technical point of view.

It only records the areas of technical agreement and identifies areas of technical disagreement.

The field survey report generally does not contain opinions on the root cause of damages, since that often requires exhaustive investigations into the events leading up to the incident.

\section{The Function of the Field Survey Report}

Once signed, the field survey report will perform a number of functions.

- While not completely public, the information provided in the report fairly states the situation known at that time and therefore reduces future misunderstandings.

- If at a later stage an additional interested party is identified who is not familiar with the matter, it fairly reports the activities to date.

- In many ways the field survey report is a specification for operational actions to be taken from that point.

- A shipyard can prepare a repair bid from a field survey report. Accounting and adjusting personnel can use it to code invoices.

- The attending parties can use it as their checklist for actions to be taken. 
- Further down the resolution of the matter, it establishes which cost items are agreed as related to the incident and which are not.

- When invoices are presented it can be used as a basis for cost negotiation.

- If one major contractor performs the repair work, the field survey report can be used as the framework for cost itemization, which greatly simplifies cost adjustment.

- When individual expert reports are prepared it becomes the source of information upon which their opinion is based. It is a generally accepted rule that the final report should reflect the field survey report.

- It eliminates "Monday morning quarterbacking". Since all parties were present, or at least were invited, it becomes difficult to second-guess any decisions made.

- It assists attorneys in determining which areas are subject to technical factual dispute and which areas are not.

- Often investigations take on a start and stop character where it is often difficult to determine where the investigations ended or when the last activity took place. A field survey report and the supplementary reports serve as a concise record for recreating the preceding activities.

- Most importantly it will reduce the scope and size of any subsequent disputes, which inevitably is a great cost saving for all parties concerned, and which is an ethical duty for engineers engaged in technical activities.

\section{Application to Non-Marine Incidents}

The author of this paper, and the firm he is associated with, has used the joint field survey method in various non-marine settings, where it has proven to serve very effectively.

In many situations the process transfers perfectly to non-marine issues.

However, since the parties in non-marine incidents are not familiar with the process it is quite uncommon that the process can be applied in full in a nonmarine setting with everybody's full understanding of its benefits.

It can be very unnerving even to the most capable engineer to be at an inspection and to be requested to participate in the generation of a joint document, and to sign it. 
Nevertheless many of the components of the joint field survey and reporting process can be extremely helpful in the resolution of a damage incident.

Recently the author of this paper was asked to inspect components for a recycled paper mill that were damaged when they fell off a truck on behalf of underwriters.

At the time the author attended, various underwriters' representatives had already attended, but none were able to develop a damage resolution process with the Owner of the components.

This was very much related to the fact that the components were not new and showed various types of wear, and that there were significant uncertainties with regard to repair procedures.

A survey was performed using the field survey process outlined above and a field survey report was written.

The field survey report concept was entirely alien to the Owner's engineer and the Owner's insurance claims department.

Consequently the Owner's engineer was directed not to sign the field survey report.

Nevertheless, the Owner's engineer reviewed the field survey report and changes were made at his request.

The resulting document recorded a level of agreement on a repair approach. and consequently enabled the resolution of the matter to proceed.

Prior to the undersigned's attendance the Owners were quite dissatisfied with the claims process. Such dissatisfaction can easily lead to escalation in the process of resolving the matter and subsequent litigation.

Upon completion of the field survey report both parties were in agreement about a way to proceed and were aware which issues were concluded and which issues required further investigation.

Another time this author was asked to represent a shipping company that had a drinking water cooler fail in their office.

The water cooler was located in an ocean shipping company office in Atlanta. 
The shipping company office was located in a large office building, together with other tenants.

On July 4, 1990, a small component in the water cooler failed, which resulted in flooding of the shipping company office and the offices of tenants located in the building's lower floors.

This author was directed by the insurance manager of the shipping company to arrange for joint survey on this matter.

The joint field survey concept was entirely familiar to the shipping company, but completely unfamiliar to the other parties involved.

Nevertheless, a total of seven interested parties attended, including representatives of the manufacturers of the water cooler, the supplier and installer of the water cooler, and the various tenants that had incurred water damage.

The damage was inspected, repair invoices and estimates were reviewed, and the failed unit was inspected.

At all times all attending parties were given the opportunity to provide their input and to ask technical and cost questions.

Since various parties were directed not to sign any documents no field survey report was produced. Nevertheless documents were exchanged, measurements were made, and there was general agreement on repair costs.

Upon completion of the survey all parties were fully aware of the technical and cost issues involved in the matter.

This author prepared his report, and the matter was litigated on legal liability issues.

Due to the joint survey there was very little testimony that related to extent of damage, repair and cost issues.

At the same time there was no dispute about physical issues such as the condition of the failed connection during the cause phase of the trial.

As a whole the trial was short and clean, while without the joint inspection there would have been endless disputes about the extent of damages, repairs and repair costs. 
The joint field survey approach had resulted in a substantial cost saving to all parties concerned.

\section{Involvement by The Legal Profession}

It has happened on many occasions, both in marine matters and non-marine matters, that the author's firm is engaged to act on an incident and is instructed by attorneys not to agree on anything or to sign anything at all.

This is understandable from an attorney's point of view, since an admission of liability in the field results in a very difficult defense to a claim.

However, as engineers, it is important to point out that there are two types of facts; engineering facts, and legal facts.

If properly recorded, engineering facts are indisputable from a technical point of view.

Legal facts are a larger group of facts that includes not only engineering facts, but also less exact and more disputable concepts such as engineering opinions, witness statements and witness points of view.

If two engineers representing opposing interests stand next to a tape measure, and they agree that the tape measure is properly calibrated, and that they are reading the same measurement, it becomes an engineering fact.

If the same two engineers using different tape measures take the same measurement, but at different times, chances are that it becomes an engineering dispute, and two useless legal facts.

While this is a simple example, the concept carries very deeply in engineering analysis.

Most of all, a potential engineering dispute should first be discussed between well trained and reasonable engineers, before it gets carried to a more complex level between opposing legal advocates.

The most dangerous course an attorney for claimants can take is not to allow the defendant's technical expert to be involved in the repair and cost approval of a damage.

Even when proceeding with the best intentions of performing repairs in the most economical manner, all things being equal, there is a fifty percent chance 
that the defendant's expert can think of a better or less expensive method to make the repairs.

If the defendant's expert did not have an opportunity to express his ideas at the time the repairs are being instituted, he has to wait to express his ideas in his individual report once the repairs have been completed and he is presented with the repair bills.

At that time he can fairly claim that the claimant spent more than reasonably necessary, and the claimant might not be reimbursed all his costs.

In those situations the only winners are the repair contractors.

Therefore when engaged to evaluate a technical matter an engineer should impress upon attorneys that the engineer realizes that he should not provide opinions on issues that are not related to direct observation, but that at the same time they will explore areas of potential technical and cost agreement based on their observations, and be consistent in those opinions in the course of the dispute.

It is interesting to note that at the moment British Courts are undergoing the effects of procedural reforms first proposed in the so called "Woolf Report". A significant portion of the reforms is related to expert witness issues.

Within the context of this paper a particularly interesting reform concept is the meeting of expert witnesses.

The meeting of the expert is described as follows:

\section{Meetings of expert witnesses}

H2.19 A meeting or meetings of expert witnesses before trial will normally be ordered. Sometimes it may be useful for there to be further meetings during the trial itself.

H2.20 The purposes of meetings of experts are to give the experts the opportumity:

a. to discuss the expert issues;

b. to decide, with the benefit of that discussion, on which expert issues they share or can come to agree the same expert opinion and on which expert issues there remains a difference of expert opinion between them (and what that difference is). 
(In the Commercial Court this description of the purpose of the meetings takes the place of the description at CPR 35.12(1)).

H2.21 Subject to paragraph $H 2.24$ belon, the content of the discussion between the experts at or in comnection with a meeting is without prejudice, and in particular (in accordance with CPR 35.12(4)) shall not be referred to at the trial unless the parties agree.

H2.22 Subject to any directions of the Court, the procedure to be adopted at these meetings is a matter for the experts, not the parties or their legal representatives.

H2.23 Neither the parties nor their legal representatives should seek to restrict the freedom of experts to identify and acknowledge the expert issues on which they agree (i.e. on which they share the same expent opinion) at (or following further consideration after) meetings of experts.

H2.24 At or following their meetings the experts should prepare a joint memorandum for the Court recording:

a. the fact that they have met and discussed the expert issues;

b. the expert issues on which they agree (i.e. on which they share the same expert opinion);

c. the expert issues where there is a difference of expert opinion between them, and a summany of what that difference of expert opinion is.

(In the Commercial Court this automatic requirement applies notwithstanding the Court's powers under CPR 35.12(3)).

While the concept is very reasonable, it can be argued that the meeting of the expert witnesses after the repairs have been made and after the evidence has disappeared is a case of rearranging deck chairs on the TITANIC.

Nevertheless it is evident that the British legal profession senses that there is something lacking in the resolution of technical disputes by using opposing experts that are constrained in technical conversation during the investigation of a damage incident.

It is clear that the joint field survey approach eliminates the need for a meeting of the experts, and moreover improves on it by doing the right things at the right time. 
It is interesting to note that recent papers by US legal professionals also seem to focus on removing some of the extreme adversity that exists in the legal profession.

For example the New York State Bar Association's Presidential message of November 1998 reminds its members to "constantly bear in mind that our primary goal as lawyers is not to win at any cost, but to resolve the dispute within the framework of the law"

\section{Conclusion}

As is noted above, an engineer, trained to provide services based on physical concepts, can often find himself in apparent conflict with external constraints when assisting in the resolution of damage incidents.

It is very important to realize that an engineer, in his responsibility to his client and to the public in general, is duty bound to provide the best possible solution to any problem.

A joint field survey approach can go a long way towards enabling engineering professionals to define the technical issues and enables the legal profession to focus on the items for which no technical agreement can be found.

\section{Acknowledgement}

The author would like to acknowledge his father, Henk van Hemmen, for his unrelenting efforts in keeping the jointness concept in the forefront of technical incident investigations as the Chief Surveyor of the United States Salvage Association, the Chairman of the Association of Average Adjusters and the senior partner at Martin, Ottaway, van Hemmen and Dolan.

He has single handedly trained a new generation of engineers and attorneys in the use of the joint field survey concept and thereby has saved, and continues to save untold millions of dollars in unnecessary expenses by insisting on the use of the concept. 